\title{
The vision of sustainable sport in a backcasting research
}

\author{
ALEXANDRA KÖVES* ㅁ, ATTILA SZATHMÁRI and ORSOLYA HERR
}

Institute for Business Economics, Corvinus University of Budapest, Hungary

Received: February 1, 2021 • Revised manuscript received: April 2, 2021 • Accepted: April 14, 2021

Published online: July 29, 2021

(C) 2021 The Author(s)

\section{ABSTRACT}

It is now becoming widely accepted that our economy has reached the limits both in terms of the carrying capacity of our planet and in terms of bringing real social justice to the table. Degrowth is a research area that aims to transcend mainstream approaches. While moving beyond the growth paradigm would entail serious changes in all areas of social life and Degrowth research extends into most of them, the transformation of sports is not among them. Neither is Degrowth a recognised concept among those who deal with sports. The participatory backcasting research introduced in this paper attempts to fill this void. In the backcasting project, master students of sports economics envisioned the sustainable future of sports and identified potential intervention steps that lead towards such normative states. This paper describes the results and assesses those elements that aim for strong sustainability. The results show that relocalisation and the sharing economy are the most accepted Degrowth concepts in a normative scenario on sustainable sports in this group. At the same time, the paper offers frameworks of thoughts for those who want to move beyond the slogans of sustainability either as responsible citizens or in positions related to the world of sports.

\section{KEYWORDS}

sustainability, backcasting, Degrowth, sports, participatory research

\section{JEL CODE}

Q56

\footnotetext{
*Corresponding author. E-mail: alexandra.koves@uni-corvinus.hu
} 


\section{INTRODUCTION}

On the level of rhetoric and everyday speech, sustainability is becoming an exceedingly fashionable word in political, social and economic discussions. However, in science there is a significant ongoing discourse on what sustainability really is (e.g. Kuhlman - Farrington 2010). While it is beyond the scope of this paper to discuss this issue in depth, one distinction in the sustainability debate must be pointed out to put the research described here in context. Assuming weak or strong sustainability predetermines certain aspects of the discussions (Ekins et al. 2003; Hopwood et al. 2005; Málovics - Bajmócy 2009; Pelenc - Ballet 2015). These terms were first applied by Pearce (1989) and later 'codified' by Neumeyer (1999) to point out a crucial difference in the sustainability debate: whether the substitutability of natural capital stocks with man-made capitals stocks should or should not be allowed. This division determines whether natural capital stocks should be maintained regardless if other capital stocks grow or not. Hence, in the case of weak sustainability, the depletion of natural capital is acceptable if the total capital stock remains constant or grows, while strong sustainability is more restrictive. Regarding renewable resources, utilisation should not exceed nature's regenerative capacities; while the consumption of non-renewable resources in any case reduces the welfare of future generations (Daly - Cobb 1989). This implies that while throughput growth is acceptable in the weak sustainability scenarios; strong sustainability prompts either a steady-state economy (Daly 1977) or Degrowth (Latouche 2009).

When mapping the different views of sustainable development, Hopwood et al. (2005) use a two-dimensional evaluation grid where on the one hand increasing environmental concerns and on the other increasing socio-economic well-being and equality concerns impact the way we think about sustainability. In their recommended analytical framework, ecofeminist, ecosocialist and indigenous movements are the ones that are concerned with both of these dimensions to their fullest extent. Degrowth relies heavily on the historical development of these movements (D'Alisa et al. 2016), and this is the reason why we aim to use Degrowth concepts as a framework of our analysis rather than general sustainability transitions or the steady-state economy.

While neoclassical economists believe that achieving (weak) sustainable development is possible with maintaining the centrality of economic growth in our theoretical approaches, alternative research fields like Degrowth prompts new ways of approaching social and economic institutions to establish an environmentally and socially more just economy (Latouche 2009; Kallis et al. 2020). Degrowth does not only provoke in terminology (Drews - Antal 2016) and in ways we do research (Spash 2010) but requires leaving the realms of paradigms underlying current economic thinking and sustainability behind and delineating a world where strong sustainability is the norm. Promoters of such strong sustainability believe that the acceptable transitional paths involve consuming less and reviewing our approaches to making business (Málovics et al. 2008; Khmara - Kronenberg 2018) as well as organising our economic and social lives (Heikkurinen et al. 2019; Kallis et al. 2020).

The world of sports is no exception. Since sport has become global, elite sport is one of the most competitive and accelerated subsystems of human activity within the economic system (András - Havran 2014). The high interest generated by sports mega-events (Olympic Games, Football World Cups and European Championships) leads to a situation where consumption, travel, and the moving of goods are concentrated in a small area for a short time. This results in 
a trade-off challenge and generates a significant environmental impact. Events potentially affect local ecosystems; utilize reserves of exhaustible natural capital and contribute to carbon emissions related to climate change. Hence, on the one hand sport is seen as a potential means of making a profit, on the other it depends on more and more resources, enormous infrastructure, and features mass tourism and giga-merchandising (Szathmári - Kocsis 2020).

A good example for the controversial relationship of sports, sustainability and profit-seeking are the Olympic Games. Decision makers of mega-sport events like the Organizing Committees of the Olympics face issues regarding where the future of the event may lie. There are questions regarding how far current tendencies of sporting activities can be developed to be more sustainable, or how far the justification of negative externalities can be attained by strategy variations (Morrison et al. 2006). In the last few decades, the content, size, and complexity of the Olympic Games (OG) has dramatically increased. Overall, the price of the OG rose to $156 \%$ of the originally projected budget; this amount of overflow needs to be managed by the host city. Therefore, the experts recommend downscaling the Winter OG, being more flexible, fighting cost overruns and gigantism as well as avoiding 'white elephants'.

However, it is not just ecological sustainability that presents a problem. The other important pillar of strong sustainability is social sustainability, where keywords include quality of life, education, equality, community development (Szathmári - Kocsis 2020). These values are essential now and for future generations. From an athlete's point of view a growing body of research has shown that pressures and resources of careers in elite sport restrict lifelong sustainability as an elite athlete, and a short-term career in sport does not prevent longer-term career sustainability in other domains. An increasing number of jobs/careers are becoming unsustainable due to high employer and contextual demands, occupational stress, burnout, and lack of work-life balance (Richardson et al. 2020). Nonetheless, it is not just in the individual sphere where social sustainability problems may occur in the world of sports. Having turned the sector increasingly towards a merely profit-seeking business also has a rather controversial relationship to building social capital, something sport has been seen as an important contributor to (Spaaij - Westerbeek 2010).

In a Degrowth or post-growth transition the way we organise, exercise, or consume sport must change and integrate both ecological and social sustainability elements. The area of sports is especially interesting in a transition as it blends the civil and state sector with relatively clear social goals (Waardenburg 2016) and a largely profit-seeking business sector with clear monetary aims meddled with interesting social utilities like community building; social identity building; or health promotion (Spaaij - Westerbeek 2010). The occurrence of sport business is relatively young compared to other areas, the professionalisation and commercialisation of sport only occurred in the last three decades of the $20^{\text {th }}$ century (András 2003). Therefore, one would assume that ways are not set so strongly as in historically profit-oriented spheres. Degrowth researchers have not examined the world of sports extensively (only tangentially in relation to sustainable tourism, e.g. in Adriotis 2018), nor is the Degrowth concept familiar to sports management literature.

The wider aim of this research was to contribute to the operationalisation of the strong sustainability paradigm in sports and identify elements that may serve as potential steps in a Degrowth transition. As the backcasting involved only a narrow range of future experts (sport economics master students) and a robust framing of the dialogues would have limited the freedom of deliberations important to participatory research methods, the research goal was limited to the topic of sustainability without introducing the concept of Degrowth to participants. 
Therefore, the research question focused on what kind of sustainability elements occur in the deliberations of a group of attentive young would-be professionals on the future of sports when using the backcasting framework. It is the aim of this paper to delineate those elements in the research that may support Degrowth transitions from those that only aim at weak sustainability.

This paper consists of three main chapters. First, we introduce the methodology. Second, to make the results of such a complex qualitative investigation concise, we use vignette techniques to highlight the main messages that arose during the three-day workshop. Third, we provide points for discussion by analysing the results in terms of their compatibility with Degrowth transitions.

\section{METHODOLOGY}

The formation of our social institutions (including our systems of rules and norms) and our expectations regarding their operation are influenced by the moral, philosophical and scientific foundations behind them, which over time can become so natural that we no longer question their legitimacy. Moreover, as time goes on, solidified institutions can already mean coercive trajectories, further strengthening the legitimacy of the fundamentals as reality begins to 'adapt'. While our thoughts shape our institutions, our institutions influence our thinking. That is why what we consider possible, desirable, and feasible in the future strongly influences what we are willing to do or not do in the present. However, to move beyond mainstream approaches in solving a complex problem such as sustainability, one must be able to leave behind the dominant frame of mind. A suitable method for this is the so-called backcasting technique (Robinson 2003) that provided the methodological framework for this research.

This backcasting research is a constructivist, policy-oriented, participatory enquiry into what sustainable sport could mean to a group of future professionals. While forecasting looks from the present towards the future and attempts to extrapolate current trends into future scenarios, backcasting turns this logic upside down (Quist et al. 2011). In many areas, such as strong sustainability, current trends fail to lead to acceptable scenarios and therefore system change is needed. However, to know the direction and the orientation of system change, a desirable scenario is required to be able to work our way back to the present and see what actions may gear the system towards such an ideal state. Backcasting does not attempt to predict the future, nor does it say that if you implement all identified intervention steps, you will certainly reach such a state. All it aspires is to gather knowledge on what could be a worthwhile condition to be in and to identify possible actions in the present that are more likely to lead towards such directions than non-action. Using the framework of backcasting, due to its nature of utopian thinking, and the psychological safety and intellectual independence it provides, participants are more likely to follow responsible and sustainable mind-sets even without such framings (Köves - Király 2021). Participatory backcasting relies on the expressions of stakeholders of their understanding of the problem itself; their demands and desires towards the future; and their identification of potential paths that may lead towards them. Therefore, Quist et al. (2011) identify five main steps in a participatory backcasting project: 1) Strategic problem orientation; 2) Future vision development; 3) Backcasting analysis; 4) Future alternative - follow-up agenda elaboration; 5) Follow-up. This backcasting on sustainable sport was an exploratory research and therefore, it only included the first three phases and the elaboration of the future alternative but did not plan or implement follow-up action. 
Participating stakeholders need not be experts of the field, lay knowledge in such participatory exercises is widely accepted (Robinson et al. 2011). After contemplating different options on participants (e.g., involving the whole management of a sports club or setting-up an 'expert panel' made up of athletes, sport media journalists, sport managers, academics, etc.), our choice fell on master students in sports economics. They have sufficient insight into the topic without being set in their ways due to long professional experience, making them ideal participants in this meaning-making exercise. Also, the stakeholder learning experience of this backcasting (Quist - Vergragt 2006) is a noteworthy tangential benefit. As involving students in a full threeday research would either require substantial funds (but paying them distorts their roles as participants) or immense internal dedication towards the sustainable world of sports (that is a relatively rare combination). Hence, we decided to accredit an elective university course called 'The sustainable future of sports' building in all the methodologies of a regular participatory backcasting research. In such a way, we ended up with a group of 15 motivated master students interested in sports management, most of them participating in dual training courses, i.e. working in sports management or economics while studying.

Within the course in November 2019, the students participated in the backcasting process for three consecutive days. In the first part of the process, students created a common vision for the distant, yet foreseeable future (2050), using the world café method. During the second day, the focus points of the vision were selected and the steps leading to them were determined using an adapted version of the futures wheel brainstorming method, while on the last day, the system-level connections were explored using the methodology of system-mapping.

The world café method is a creative process designed specifically to facilitate collaborative conversations and knowledge sharing (Brown - Isaacs 2014). Participants discuss a predefined question or topic in small groups moving regularly to other tables 'fertilizing' the conversations with thoughts, ideas, and attitudes from previous rounds. During this exercise, there were 20-20 min to discuss 2-2 topics at 3 tables ( 6 topics altogether). The topics selected by the students in the first hours of the course using story cubes were infrastructure, technology, social cooperation, economic activities, culture/entertainment, transport. Using the method, the vision of the sustainable future of sport outlined by the students was developed by the end of the first day.

On the second day, a modified version of the futures wheel method was used (Glenn 2009). During this phase, students followed the operative interconnection of time dimensions and applied the method of the futures wheel with a reverse logic: they did not place a present trend or event in their centre, but a desirable vision of sustainable sports. The wheel thus explores the conditional system of the desired vision, the path leading to it and its internal connections. Six main focuses of the vision were selected by a group decision: the role of the state (involvement for sports support); sustainable events; the athlete's perspective; community funding; virtual space; and the issue of sustainable sports equipment and infrastructure.

Participatory system mapping is a method that builds a conceptual model mapping the elements/variables of a complex issue or problem (Király et al. 2015). The preparation of this system map (complex causal diagram) reveals the structure of the given topic together with the obvious and hidden connections between the variables. In a participatory environment, system mapping serves to explore the attitudes and mental models of individuals or groups so that they can express their assumptions about causes and effects and broaden their conceptualisation of the problem by thinking through how elements interrelate. A system map can be created during 
backcasting to understand and see which area of intervention can most effectively affect other factors. Table 1 presents an overview of the methodology.

Before providing an overview of the deliberations across three days, it is important to note that topics were not framed in any way before or during the course. Preparatory materials made sure that no expressions suggest what students are expected to say. The attention was only drawn to the fact that sustainability entails social sustainability as well as ecological sustainability. During the course, the researchers (in the eye of the students the tutors) did not express their opinions and made sure that they acted only as neutral facilitators of the process and the discussions.

As seen from Table 1, the outputs contain results in various forms. In order to present them in a comprehensive format, this chapter relies on the use of vignettes. As Reay et al. (2019: 202) put it, presenting qualitative research data that tell a convincing and interesting story can be a challenge and 'rigour can become rigor mortis'. In the vignette approach, the researchers highlight focal points that make readers understand the interconnections and narratives of the qualitative data in an easy-to-follow format. This serves as the illustration of themes that occur during the research (Reay et al. 2019). The outputs and the deliberations during this backcasting research revolved largely around the themes in Fig. 1, which is an example stream of how deliberations and concrete outputs evolve into vignettes.

Based on their own framing, participants developed topics that served as inputs to the discussions around the world café tables. These discussions resulted in the textual vision that was later organised around six central focuses that served as focal points for the development of the backcasted intervention steps that could lead to the future they imagined. Based on the intervention steps, variables were identified by the participants to build up the systems map of sustainable sports. These outputs and deliberations were distilled by the authors into vignettes that provide the basis of describing the results in the next chapter.

\section{OVERVIEW OF THE RESULTS}

Before going into the details of the results, it is important to note that the literature dealing with sports almost always makes a difference between mass and elite or professional and amateur or

Table 1. Overview of the methodology

\begin{tabular}{|c|c|c|}
\hline Backcasting step & Internal methodology & Outputs \\
\hline $\begin{array}{l}\text { 1) Strategic problem } \\
\text { orientation }\end{array}$ & $\begin{array}{l}\text { Imagination games and workshop } \\
\text { techniques with story cubes }\end{array}$ & $\begin{array}{l}\text { Six topics to discuss around the } \\
\text { world café tables }\end{array}$ \\
\hline 2) Develop future vision & World Café (Brown - Isaacs 2014) & 2-page long vision (920 words) \\
\hline 3) Backcasting analysis & Modified futures wheel (Glenn 2009) & $\begin{array}{c}6 \text { charts on the backcasting steps, } \\
\text { altogether } 121 \text { recommended } \\
\text { interventions }\end{array}$ \\
\hline $\begin{array}{l}\text { 4) Elaborate future } \\
\text { alternative }\end{array}$ & $\begin{array}{c}\text { Participatory systems mapping (Király } \\
\text { et al. 2015) }\end{array}$ & $\begin{array}{c}\text { System map on the vision with } 53 \\
\text { variables }\end{array}$ \\
\hline
\end{tabular}

Source: authors. 


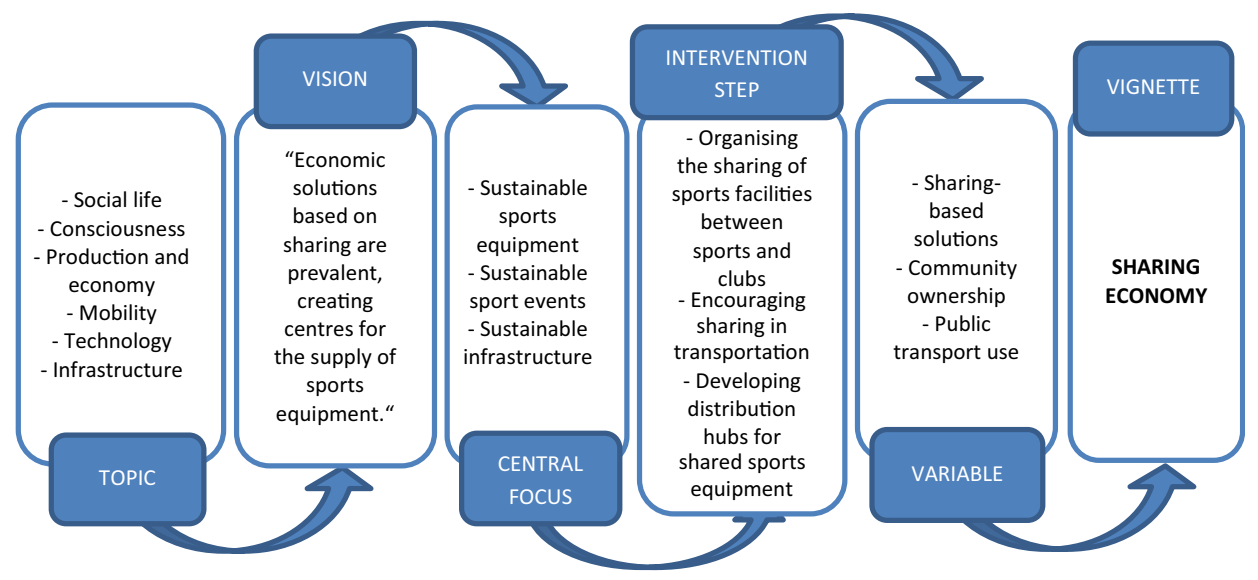

Fig. 1. An example stream for the evolution of vignettes based on the outputs Source: authors

competitive and recreational sports. When enabling participatory deliberative dialogue on the sustainable future of sports, we have consciously not framed the research to make these distinctions as they are intertwined, constantly interacting with each other and they all need to make a transition to a more sustainable path. In hindsight, this proved to be an effective approach as many of the discourses revolved around the intersections of these different perspectives and the solutions suggested by the participants often involved all these perspectives. In terms of sustainability, exercising as a hobby, competing as an amateur or as a professional and consuming sports in any forms has significant relevance.

\subsection{Environmental sustainability}

3.1.1. Sharing economy. The concept of the sharing economy (Frenken - Schor 2017) was by far the most well-known green alternative among the participants. They found it highly relevant in the world of sports and applied its model to many of the solutions they proposed. Their textual vision includes the following:

"Economic solutions based on sharing are prevalent, creating centres for the supply of sports equipment.

The tools used by professionals are utilized on other levels; rental options are more widely available and, like the draw for horses in the pentathlon, self-ownership is not mandatory in many sports."

In their vision sharing can be applied to most sport equipment (the higher the ecological cost of owning one, the more it should be encouraged to be shared among the athletes). They pointed out that such solutions already exist as for example in the pentathlon, horses are drawn to competitors rather than transported across the globe from wherever its rider comes from. Discussions on sharing occurred ranging from the simplest equipment such as tennis balls to the more complex and resource intensive technical sports such as motorsports. According to the participants, this way the highest ideal of sports, i.e. the greatest achievements of human capability itself can become the centre of attention rather than limited accessibility to own an equipment. Along similar lines, sharing was considered also a good tool to achieve social 
sustainability where the participants focused a lot on providing level playing fields to all with regard to accessibility to any sports.

Three variables cover the topic of the sharing economy in the final system map: Sharingbased solutions; Community ownership; Public transport use and seven intervention steps recommended like the creation of distribution centres or the drafting of agreements between clubs or different sports on how to share resources. Interestingly, most related intervention steps are recommended for 2020-2030. It shows how the participants believed that this is a low-hanging fruit ready to be explored if the world of sports is to become more sustainable.

3.1.2. Multifunctionality. As described above, using less resources for sports was often in the centre of discourse. The vision proposes the following:

"There are facilities with flexible capacity that treat social equality (people with reduced mobility, the elderly, young children) as a priority, that can be changed according to current needs and shaped depending on the number of viewers. At the same time, they are multifunctional and suitable for organizing several sports and other cultural events. Their vertical exploitability also appears."

The multifunctionality of sports infrastructure is also a variable in the system map of sustainable sports. Multifunctionality occurred as a theme in many different directions: the sharing of the same space by different sports; the sharing of the same space by sports and cultural events; and the sharing of the same space with other local actors such as schools.

3.1.3. Event organisation. Sustainable event organisation became a central focus during the backcasting analysis phase. Not one particular system map variable can be attached to this vignette as it appears more like a horizontal theme. It more strongly relates to the following principle the participants followed during the discourses: the ecological footprint of organising as well as participating in sports events should continuously be taken into account and the decision on whether or not or how to hold an event should be based on community considerations. As the vision states: "The ecological footprint of major global sporting events is accurately calculated, and a global referendum decides what to give up for the event." The example they use is the Olympic Games that could be organised regionally in a series of smaller events reducing the footprint or - as a fictional option even in 2050 - using a 'mobile Olympic city' that does not require such huge infrastructural investments. As they envision conscious individuals carefully monitoring their footprints, their own participation is subject to sustainable modes: "In connection with sports events, the use of public transport, renewable resources, the sharing economy and environmentally conscious decisions in the choice of forms of transport come to the fore." The recommended steps (27 relating to sustainable event organisation) revolve around three main themes: 1 ) how to calculate; 2) how to reduce the ecological footprints of events; and 3) how to rank events according to their environmental impact. All this in need to feed adequate information into systems of participatory decisionmaking.

3.1.4. Relocalisation. As seen also from the previous vignettes, participants sought ways to reduce the ecological impact of sports and in this effort, localisation has taken centre stage. However, relocalisation is not a tool just for environmental sustainability but also for social sustainability. Four system map variables relate to this topic: localisation; decentralisation (of 
decision-making); local consumption; strength of local communities (covering 10 intervention steps). The vision and the backcasting steps emphasise the contribution of sports to building strong communities by reinforcing identity, setting examples, enhancing local consumption and production circles, and interlinking sports with education. Community involvement should influence the financing of sports as well:

"The basis of the financial support of sports is the need of the community to practice and / or consume the given sport. The decision can be interpreted at the local / national / global levels. In this light, support may come from socially conscious economic actors, local communities, or public sources. This community-based funding provides a low entry threshold for accessibility for community members."

The production of sports equipment should also account for geographical distances and manufacture as locally as it makes the most sense in terms of ecological efficiency.

3.1.5. Role of technology and the virtual world. The participants have shown immense technological optimism. In all their endeavours, technology was seen as an ally enabling the visions to come true: Technology makes sports more enjoyable both locally and from the comfort of one's home. It is called upon when designing multifunctional infrastructures; measuring ecological footprint; encouraging sharing; facilitating both local and global decisionmaking; and enhancing human health. The only reservation expressed is that it should not replace humans:

"Technology is supportive to sports, but it is no substitute for humans. Technological help can be used to promote equal opportunities, but because of the purity of sport, people continue to compete without technological help. In experimental cases, robot-human competitions exist. Technology improves gameplay and supports the work of the referees but does not completely replace them."

Twenty-nine recommended backcasting steps relate directly to technology. In the systemmap the following variables appear directly to technology: availability of green technology; availability of smart technology; availability of virtual tools; and Internet coverage. However, indirectly there are also the following: sharing-economy solutions; availability of renewable energy; life cycle of products; and recycling.

Some of the most avid debates revolved around the role of the virtual world in sustainability. Finally, the acheived consensus was to include a paragraph on the virtual world in the vision:

"In 2050 sport is still predominantly about entertainment, present both in virtual and physical spaces.

As technology advances, new sports are created, but old sports are also preserved through rule changes.

E-sports are widely practiced and have the same professional background as traditional. However,

even for e-athletes, healthy physical exercise is important."

The healthy physical exercise meant that they decided to make virtual reality one of the six central focuses in the backcasting analysis phase. This resulted in 18 intervention steps ranging from the support of e-athletes and e-sports through the availability of VR tools for enhancing training techniques to the use of VR in enhancing the experience of watching sporting events. 


\subsection{Social sustainability}

3.2.1. The impact of sports on individual and social responsibility and consciousness. The topic of responsibility and consciousness in relation to sustainability and with regard to sports' contribution to it was raised on a number of different levels: from individuals as consumers; to global governance bodies in the world of sports. Four variables were identified that directly relate to this issue: consumer consciousness, citizen consciousness, social responsibility, and real CSR (of companies). However, indirectly it also concerns the variables of transparency and participation (in decision-making). Participants believed that sustainable sports can only come about if all actors reach high levels of consciousness and social responsibility. This can be done through communication and awareness-raising on the individual level and regulatory and incentivising means on the economic level. The presumption was that it happens on the governmental level if decentralisation and the introduction of participative decision-making brings individuals and political actors closer to each other.

3.2.2. Accessibility and social mobility. The following quote from the vision reflects well the deliberations around this issue during the backcasting research:

"In 2050, as a result of globalisation and technological advances, sport reduces the gap between social groups. The role of money is diminishing, which is reflected in the realisation of unrestricted access to sports equipment and sports activities on the one hand as a consumer for the experience of participation, and on the other hand as an amateur and professional athlete. Along these lines, freedom of sport choice can be realised, and more conscious sport choices help social mobility, reduce tension, create equal opportunities, and gain a sense of success."

Accessibility was a chosen central theme for the backcasting analysis phase. They also believed that accessibility and equal opportunities are the keys in raising the number of amateur and professional athletes in sports that should be the ultimate goal in maintaining health and good social connections. The 25 related intervention steps cover clearing physical and monetary barriers to mass sports; provide opportunities (even with the use of VR) for anybody to choose the sport that fits them best; support talents and make sure that professional athletes are not abandoned at the end of their careers. In the system map three variables relate directly to this: accessibility, freely available sporting opportunities, and equal opportunities. Strangely, social mobility does not occur as a variable.

3.2.3. Sustainability and the individual athlete. On the one hand, participants believed that an athlete should advance social and environmental responsibility through exemplary and motivated behaviour. As sports are popular with a wide range of people, an athlete can motivate many at once to preserve values and nudge them towards responsibility and consciousness. On the other hand, participants were concerned with the social sustainability of the athletic career itself and considered it important for an athlete to be career conscious, to learn, and to develop beyond the world of sports and active competitions.

Based on their vision, participants picked the 'athlete's perspective' as one of the six central focuses of the backcasting analysis phase. The 21 related intervention steps revolved around four main goals: develop a system that integrates the athlete into the labour market; operate dual career building systems; develop their roles in exemplary consumer behaviour (e.g. in 
environmental protection); and locally involve professional athletes based on their own initiatives.

\section{ANALYSIS OF THE RELEVANCE OF THE RESULTS FOR A DEGROWTH TRANSITION}

This chapter aims at assessing what elements of the discourses that occurred in our participatory research reflect Degrowth principles and which stay within the realms of mainstream economic approaches. It also pinpoints those concepts that can be evaluated as strong sustainability and those that remain within the narrative of weak sustainability.

The central message of Degrowth is the realignment of economic and social activities where the unchallenged importance of economic growth no longer plays a significant part (Kallis et al. 2020). Economic activities must account for ecological and social limits to growth. The current dominant logic of neoclassical economics where growth plays an important role has never been questioned by the participants. (This result may have be driven by the fact that they were economics students.) However, they have started considering ecological limits. For example, all along they accepted that certain trade-offs based on social dialogue must be accepted in sports also. Even though Olympics are a wonderful event in sports, the acknowledgement of ecological limits may prompt its redesign or even cancellation.

This is in line with current trends. When it comes to the future of the OG, experts see the reduction of costs for bidding and staging the OG as well as the turn out to be adaptable in the Games' management as key suggestions (Schnitzer et al. 2019). Preuss (2013) raised the issue how reasonable it is to anticipate a sports mega-event to hold a sustainable legacy. In his assessment, he claimed that the matter of the green programmes differs widely from presenting high-priority projects, which are well noticeable to less visible. He recommended that the initial action towards sustainable events is taken when the international sports organisations incorporate eco-friendliness as a strategy. However, even the greenest approaches to event reorganisation would not question the ultimate aim, the telos of such events.

The emphasis on sharing throughout the deliberations is a concept familiar in Degrowth research (Kallis et al. 2018). There is a significant attention to the sharing economy as a way of fostering sustainable consumption habits. Heinrichs (2013) has touted the sharing economy as a possible modern pathway to sustainability, whereas Botsman and Rogers (2010) claim that it will unsettle the unjustifiable habits of over-consumption that drive capitalist economies. The sharing economy, due to its universal resonance, could also find its utility in the sports industry, especially in sport mega-event organization and legacy planning. These characteristics are mainly widespread in the Olympic Games, hence the trademark and biggest sports event will operate as a foundation for additional evaluation alongside creating some models of sharing economy movements that appear in former editions of the Olympic Games. Former studies reveal that distended mindfulness of ecological issues among individuals leads to a growth in environmental actions (Davies et al. 2002). As normal residents, clients, and decision-makers are becoming increasingly alert to the necessity to be environmentally watchful, initial adopters of sustainable strategy in sport are relishing appreciation as business pioneers (Solomons - Willacy 2014). Participants have shown an openness towards sharing solutions that Degrowth suggests as a possible way of reducing overall throughput. 
All in all, the participants' solutions were highly techno-optimistic and has never deliberated on the fact that technological solutions often have high environmental costs (Kerschner et al. 2018). Technological solutions assist strong sustainability when they serve social visions and solutions that take ecological limits into account. However, during this research, the reigning narrative of endless economic growth and endless potential of technological innovation has not been questioned. The rebound effects (Binswanger 2001; Parrique et al. 2019) on the savings of technological efficiency and the resource and energy demands of technological solutions remained unchallenged. Tools like teleportation, virtual reality, big data or smart devices were perceived as solutions that add to sustainability without assessing its real environmental and social costs. This confirms the reigning tendency that Degrowth literature often criticises (Nordhaus - Shellenberger 2015).

Results show that multifunctional and zero emission infrastructure has taken up much of the imaginaries among the participants. While this is still a technical rather than a structural or cultural response to sustainability issues, sports venues do offer a broad range of non-economic gains such as expanded ease of access, publicity, involvement, and success. Walton et al. (2008) concur that definite gains such as dignity, respect, community spirit, and legacy of sporting facilities tend to be ignored, mainly because they are difficult to measure (Grieve et al. 2012). Almost all these perspectives occurred during the deliberations.

Scholars recognise three principal themes, with reference to how sport can be directed towards the accomplishment of health consequences: sport should be associated with public needs; sport should be driven by safeguarding values of health; and sporting bodies should influence cooperation in health to endorse sustainability (Edwards et al. 2019). Kim et al. (2019) also argue for the creation of positive organizational practices to ensure the mental health of sports employees. Lamont and Kennelly (2019) presented the example of sporting hyper-challenges to highlight the typical market approach to sports development that has encouraged athletes to pursue physical punishment rather than healthy lifestyles, while simultaneously straining athletes' personal lives. While participants have focused on the athletes' perspectives in terms of social sustainability, the dominant perspective of sports as an entertainment industry is also noticeable when it comes to the participants' views on the athletes themselves. The instrumental perspective of the professional athletes is well illustrated by the fact that their personal wellbeing has never been discussed. It remained an underlying hypothesis that professional athletes are well-paid and healthy and - similarly to technology - when they are beyond their working capacity, they are simply replaced. When getting paid well and presumably doing what they like, they only have responsibilities of acting like role models but no rights when it comes to entertaining others to the best of their knowledge. It was only providing flexible enough solutions of learning opportunities for athletes that were stressed within the framework of social sustainability. Such instrumental perspectives are often criticised in the Degrowth literature (Kallis et al. 2020).

The most prominent approach in the debates was that the participants' focus on sports was still that of entertainment and health promotion and the important perspective in Degrowth, voluntary simplicity (Shaw - Newholm 2002) played no role. However, another central concept to Degrowth is that of conviviality (Kerschner et al. 2018) where individuals place an emphasis on enjoying themselves in a thriving community based on sharing experiences, resources and on solidarity. Even though the phrase conviviality did not appear (it is a less well-known concept in Hungary), the role of sports in securing the notions that make up a convivial society was 
emphasised. This is also in line with the deliberations that focused on the controversies between social solidarity and ecological sustainability.

When it comes to sustainability policy interventions, participants have put much emphasis on the role of legislation, but have often stressed how these were unlikely to take place due to the counter-interests political and economic decision-makers may have. This showed a complete lack of social trust in institutions that are supposed to serve the interests of current and future generations. On the other hand, this social distrust - coupled with the desire to have stronger communities - has given rise to a strong decentralised and relocalised narrative. Relocalisation (Ajulo et al. 2020), i.e. the robust network of local communities has appeared often in the dialogues giving rise to optimism that if companies have stronger local ties and municipalities have stronger authorities, a sustainability transition in sports can take place. According to participants, these tendencies should lead towards more participation and deliberation of individuals in economic and social decision-making. This is fully in line with Degrowth concepts where the autonomy of people and communities and the relocalisation of the economy should lead to stronger sustainability.

\section{CONCLUSIONS}

In this backcasting research, participants imagined a normative scenario for 2050 for the sustainable world of sports. Their deliberations revolved around key issues such as sustainable events; sustainable sports equipment and infrastructure; community-building; and the role of the state in the development of sports. Mass sports based on real physical movement were in focus, but fun e-sports also appeared in addition. It was assumed that globalisation and technological development will have a major impact on the future of sports, as these will help reduce social disparities, promote accessibility, make infrastructure environmentally efficient, and create games and sports in virtual space that provides access to sports without logistical, transportation and infrastructural demands. In their view, it is possible to reach a state where infrastructural developments and events are organized consciously and through collective decision-making within a reasonable ecological footprint. Sport continues to play a significant role in social sustainability, strengthening communities and providing space for social mobility.

In order to reach such an ideal state, participants have suggested a number of policy recommendations. Among others, these interventions focus on developing systems that calculate the ecological footprint of individual activities and consumption, events, and infrastructure. This enables not just conscious decision-making based on this information but also collective decisions on priorities and trade-offs between human entertainment and ecological burden. They would also set up a system, the current tasks of which would be to develop public opinion polls and methodologies and state influence in the development of the legal personality background. This would encourage the development of systems and technologies that are based on ecological efficiency through lower emissions and resource intensity.

Decentralisation and relocalisation was at the centre of suggestions when it came to the most divisive topic on the role of the state in sports. While they relied heavily on individual consciousness in sustainability and demanded corporate decision-makers to take their fair share in sustainability efforts, demand shifted towards strengthened local communities where strong, stable local self-governing populations are formed. In their views, this would enable socially and 
ecologically responsible local economic actors to emerge that take part in the organisation of sports that are inclusive, accessible and sustainable.

Sustainability transitions need to be around the corner if we intend to keep human civilisation running for some time to come. The world of sports will also have to adapt to new circumstances and new sustainability requirements. According to Degrowth, this can only be done through leaving reigning paradigms behind. However, this is a demanding task when we are facing numerous path dependencies and lock-in effects. Real utopias (Wright 2012) can help us understand where there is still room for improvements. This backcasting research provides us with one such narrative, with some limited features of Degrowth. It gives us some insights into what this specific group of sport economics students sees as a possible and desired normative scenario, but we must be aware that this is also a reflection on the current stages of social dialogue on sustainability. As it also reflects on the social theories dominant in the discourses of the society they operate in (Király et al. 2013), they may not apply to all societies. Nonetheless, using research tools such as backcasting can support any communities - in our case those dealing with sports - in uncovering potential ways forward.

Sport is seen as a competition and result-oriented subsystem of the economy where its contribution to social capital has hardly ever been questioned. Its business- and profit-orientation dates back to more recent times than most other sectors. Hence, successfully adapting sustainability practices to the world of sports could provide best practices to other subsystems that operate even more along the growth logic. If sustainability as a concept proves to be manageable for sports, it might also work in a broader sense: for non-sports activities that play a part in human wellbeing. Enabling Degrowth principles to take roots in such endeavours could be beneficial for both people and planet.

\section{ACKNOWLEDGEMENTS}

The authors wish to express their gratitude to the students who participated in the backcasting process and shared their knowledge and insights with them. The corresponding author's contribution was supported by the National Research, Development and Innovation Fund of Hungary, financed under the PD128624 post-doctoral funding scheme. Last, but not least, the authors would like to express their gratitude to the anonymous reviewers for their insightful comments and suggestions.

\section{REFERENCES}

Ajulo, O. M. - von Meding, J. - Tang, P. (2020): Relocalisation for Degrowth and Disaster Risk Reduction. Disaster Prevention and Management: An International Journal. https://doi.org/10.1108/DPM-01-20200012.

András, K. (2003): The Interrelatedness of Sport and Business - Theoretical Approach. Corvinus University of Budapest, Department of Business Economics Working Paper.

András, K. - Havran, Z. (2014): Regional Export Efficiency in the Market of Football Players. Theory, Methodology, Practice 10(2): 3-15. 
Binswanger, M. (2001): Technological Progress and Sustainable Development: What About the Rebound Effect? Ecological Economics 36(1): 119-132. https://doi.org/10.1016/S0921-8009(00)00214-7.

Botsman, R. - Rogers, R. (2010): What's Mine is Yours. How Collaborative Consumption is Changing the Way We Live. London, UK: Collins.

Brown, J. - Isaacs, D. (2014): The World Café. Shaping Our Futures through Conversations that Matter. San Francisco, CA: Berrett-Koehler Publishers.

D’Alisa, G. - Demaria, F. - Kallis, G. (Eds.) (2016): Degrowth - A Vocabulary for a New Era. Milton Park: Routledge.

Daly, H. E. (1977): Steady-State Economics. San Francisco: W.H. Freeman.

Daly, H. E. - Cobb, J. (1989): For the Common Good. Boston: Beacon Press.

Davies, J. - Foxall, G. R. - Pallister, J. (2002): Beyond the Intention-Behaviour Mythology. An Integrated Model of Recycling. Marketing Theory 2: 29-113.

Drews, S. - Antal, M. (2016): Degrowth: A "Missile Word" that Backfires? Ecological Economics 126: 182187. https://doi.org/10.1016/j.ecolecon.2016.04.001.

Edwards, M. B. - Rowe, K. (2019): Managing Sport for Health. An Introduction to the Special Issue, Sport Management Review 22: 1-4. https://doi.org/10.1016/j.smr.2018.12.006.

Ekins, P. - Simon, S. - Deutsch, L. - Folke, C. - De Groot, R. (2003): A Framework for the Practical Application of the Concepts of Critical Natural Capital and Strong Sustainability. Ecological Economics 44(2-3): 165-185. https://doi.org/10.1016/S0921-8009(02)00272-0.

Frenken, K. - Schor, J. (2017): Putting the Sharing Economy into Perspective. Environmental Innovation and Societal Transitions 23: 3-10. https://doi.org/10.1016/j.eist.2017.01.003.

Glenn, J. C. (2009): The Futures Wheel. Futures Research Methodology V3.0. The Millenium Project 2009: $1-17$.

Grieve, J. - Sherry, E. (2012): Community Benefits of Major Sport Facilities. The Darebin International Sports Centre, Sport Management Review 15: 218-229. https://doi.org/10.1016/j.smr.2011.03.001.

Heikkurinen, P. - Lozanoska, J. - Tosi, P. (2019): Activities of Degrowth and Political Change. Journal of Cleaner Production 211: 555-565. https://doi.org/10.1016/j.jclepro.2018.11.119.

Heinrichs, H. (2013): Sharing Economy: A Potential New Pathway to Sustainability. Gaia 22: 228-231.

Hopwood, B. - Mellor, M. - O’Brien, G. (2005): Sustainable Development: Mapping Different Approaches. Sustainable Development 13(1): 38-52. https://doi.org/10.1002/sd.244.

Kallis, G. - Kostakis, V. - Lange, S. - Muraca, B. - Paulson, S. - Schmelzer, M. (2018): Research on Degrowth. Annual Review of Environment and Resources 43: 291-316. https://doi.org/10.1146/annurevenviron-102017-025941.

Kallis, G. - Paulson, S. - D’Alisa, G. - Demaria, F. (2020): The Case for Degrowth. Cambridge, UK: Polity Press.

Kerschner, C. - Wächter, P. - Nierling, L. - Ehlers, M. H. (2018): Degrowth and Technology: Towards Feasible, Viable, Appropriate and Convivial Imaginaries. Journal of Cleaner Production 197: 1619-1636. https://doi.org/10.1016/j.jclepro.2018.07.147.

Khmara, Y. - Kronenberg, J. (2018): Degrowth in Business: An Oxymoron or a Viable Business Model for Sustainability? Journal of Cleaner Production 177: 721-731. https://doi.org/10.1016/j.jclepro.2017.12.182. Kim, M. - Kim, A. C. H. - Newman, J. I. - Ferris, G. R. - Perrewé, L. (2019): The Antecedents and Consequences of Positive Organizational Behavior. The Role of Psychological Capital for Promoting Employee Well-being in Sport Organizations. Sport Management Review 22: 108-125. http.//dx.doi. org/10.1016/j.smr.2018.04.003. 
Király, G. - Köves, A. - Pataki, G. - Kiss, G. (2015). Assessing the Participatory Potential of Systems Mapping. Systems Research and Behavioral Science 33(4): 496-514. https://doi.org/10.1002/sres.2374.

Király, G. - Pataki, G. - Köves, A. - Balázs, B. (2013): Models of (Future) Society: Bringing Social Theories Back in Backcasting. Futures 51: 19-30. https://doi.org/10.1016/j.futures.2013.05.001.

Köves, A. - Király, G. (2021): Inner Drives: Is the Future of Marketing Communications More Sustainable When Using Backcasting? Futures 130. https://doi.org/10.1016/j.futures.2021.102755.

Kuhlman, T. - Farrington, J. (2010): What is Sustainability? Sustainability 2(11): 3436-3448. https://doi. org/10.3390/su2113436.

Lamont, M. - Kennelly, M. (2019): Sporting Hyperchallenges. Health, Social, and Fiscal Implications. Sport Management Review 22: 68-79. http.//dx.doi.org/10.1016/j.smr.2018.02.003.

Latouche, S. (2009): Farewell to Growth. Cambridge, UK: Polity Press.

Málovics, G. - Bajmócy, Z. (2009): A fenntarthatóság közgazdaságtani értelmezései [Economic Interpretations of Sustainability]. Közgazdasági Szemle 56(5): 464-483.

Málovics, G. - Csigéné, N. N. - Kraus, S. (2008): The Role of Corporate Social Responsibility in Strong Sustainability. Journal of Socio-Economics 37(3): 907-918. https://doi.org/10.1016/j.socec.2006.12.061.

Morrison-Saunders, A. - Therivel, R. (2006): Sustainability Integration and Assessment. Journal of Environmental Assessment Policy and Management 8(3): 281-298. https://doi.org/10.1142/ S1464333206002529.

Neumeyer, E. (1999): Weak versus Strong Sustainability: Exploring the Limits of Two Opposing Paradigms. Cheltenham, UK: Edward Elgar.

Nordhaus, T. - Shellenberger, M. (2015): A Critique of Techno-Optimism: Efficiency Without Sufficiency is Lost. http://samuelalexander.info/wp-content/uploads/2017/02/A-Critique-of-Techno-OptimismSamuel-Alexander-1.pdf, accessed 20/01/2021.

Parrique, T. - Barth, J. - Briens, F. - Kerschner, C. - Kraus-Polk, A. - Kuokkanen, A. - Spangenberg, J. H. (2019): Decoupling Debunked: Evidence and Arguments against Green Growth as a Sole Strategy for Sustainability. European Environmental Bureau.

Pearce, D. - Markandya, A. - Barbier, E.B. (1989): Blueprint for a Green Economy. London, UK: Earthscan Publications.

Pelenc, J. - Ballet, J. (2015): Strong Sustainability, Critical Natural Capital and the Capability Approach. Ecological Economics 112: 36-44. https://doi.org/10.1016/j.ecolecon.2015.02.006.

Preuss, H. (2013): The Contribution of the FIFA World Cup and the Olympic Games to green economy. Sustainability 5(8): 3581-3600. https://doi.org/10.3390/su5083581.

Quist, J. - Thissen, W. - Vergragt, P. J. (2011): The Impact and Spin-off of Participatory Backcasting: From Vision to Niche. Technological Forecasting and Social Change 78(5): 883-897. https://doi.org/10.1016/j. techfore.2011.01.011.

Quist, J. - Vergragt, P. (2006): Past and Future of Backcasting: The Shift to Stakeholder Participation and a Proposal for a Methodological Framework. Futures 38(9): 1027-1045. https://doi.org/10.1016/j.futures. 2006.02.010.

Reay, T. - Zafar, A. - Monteiro, P. - Glaser, V. (2019): Presenting Findings from Qualitative Research: One Size Does Not Fit All. In: Zilber, T. B. - Amis, J. M. - Mair, J. (Eds.): The Production of Managerial Knowledge and Organizational Theory: New Approaches to Writing, Producing and Consuming Theory. Bingley, UK: Emerald Publishing Limited, pp. 201-216. https://doi.org/10.1108/S0733558X20190000059011.

Richardson, J. - McKenna, S. (2020): An Exploration of Career Sustainability in and after Professional Sport. Journal of Vocational Behavior 117: 103-314. https://doi.org/10.1016/j.jvb.2019.06.002. 
Robinson, J. (2003): Future Subjunctive: Backcasting as Social Learning. Futures 35(8): 839-856. https://doi. org/10.1016/S0016-3287(03)00039-9.

Robinson, J. - Burch, S. - Talwar, S. - O'Shea, M. - Walsh, M. (2011): Envisioning Sustainability: Recent Progress in the Use of Participatory Backcasting Approaches for Sustainability Research. Technological Forecasting and Social Change 78(5): 756-768. https://doi.org/10.1016/j.techfore.2010.12.006.

Schnitzer, M. - Haizinger, L. (2019): Does the Olympic Agenda 2020 have the Power to Create a New Olympic Heritage? An Analysis for the 2026 Winter Olympic Games Bid. Sustainability 11: 442. https:// doi.org/10.3390/su11020442.

Shaw, D. - Newholm, T. (2002): Voluntary Simplicity and the Ethics of Consumption. Psychology 19: 167185. https://doi.org/10.1002/mar.10008.

Solomons, M. - Willacy, M. (2014): Ipswich Council Ignored Environmental Concerns to Rubber-Stamp Stadium Earmarked as New Brisbane Lions Home. ABC News. http.//www.abc.net.au, accessed 08/07/ 2020.

Spaaij, R. - Westerbeek, H. (2010): Sport Business and Social Capital: A Contradiction in Terms? Sport in Society 13(9): 1356-1373. https://doi.org/10.1080/17430437.2010.510674.

Spash, C. L. (2010): Censoring Science in Research Officially. Environmental Values 19(2): 141-146. https:// doi.org/10.3197/096327112X13303670567134.

Szathmári, A., Kocsis, T., 2020. Who Cares About Gladiators? An Elite-Sport-Based Concept of Sustainable Sport. Sport in Society 1-19. https://doi.org/10.1080/17430437.2020.1832470.

Waardenburg, M. (2016): Which Wider Social Roles? An Analysis of Social Roles Ascribed to Voluntary Sports Clubs. European Journal for Sport and Society 13(1): 38-54. https://doi.org/10.1080/16138171. 2016.1153883.

Walton, H. - Longo, A. - Dawson, (2008): A Contingent Valuation of the 2012 London Olympic Games. A Regional Perspective. Journal of Sports Economic 9: 304. https://doi.org/10.1177/1527002507308769.

Wright, E. O. (2012): Transforming Capitalism through Real Utopias. American Sociological Review 78(1): 1-25. https://doi.org/10.1177/0003122412468882.

Open Access. This is an open-access article distributed under the terms of the Creative Commons Attribution 4.0 International License (https://creativecommons.org/licenses/by/4.0/), which permits unrestricted use, distribution, and reproduction in any medium, provided the original author and source are credited, a link to the CC License is provided, and changes - if any - are indicated. (SID_1) 